\title{
Post-Modernismo: O futuro do passado no romance português contemporâneo
}

\author{
Ana Paula Arnaut \\ Universidade de Coimbra
}

\begin{abstract}
RESUMO: DEPOIS DE UMA BREVE REFERÊNCIA ÀS DIFICULDADES LEVANTADAS PELO TERMO E PELO CONCEITO POST-MODERNISMO, APRESENTAREMOS AS PRINCIPAIS CARACTERÍSTICAS DA NOVA LITERATURA E, A PARTIR DA MÁXIMA NON NOVA, SED NOVE, VERIFICAREMOS COMO ELAS SE ACTUALIZAM EM ALGUNS ROMANCES PORTUGUESES.
\end{abstract}

ABSTRACT: AFTER REFERRING BRIEFLY TO THE PROBLEMS RAISED BY THE TERM AND THE CONCEPT OF POST-MODERNISM, WE WILL PRESENT THE PRINCIPAL FEATURES OF THE NEW LITERATURE AND, TAKING AS A STARTING POINT THE MAXIM NON NOVA, SED NOVE (NOT NEW, BUT IN A NEW WAY), SEEK TO ESTABLISH WHETHER OR NOT THEY ARE PRESENT IN A SELECTION OF PORTUGUESE NOVELS.

PALAVRAS-CHAVE: POST-MODERNISMO, METAFICÇÃO, PARÓDIA, FRAGMENTARIDADE. KEYWORDS: POST-MODERNISM, METAFICTION, PARODY, FRAGMENTATION. 
s únicos livros que podem vir a ser bons / (e nunca é certo) /

são aqueles que a gente tem a certeza de não ser capaz de escrever.

António Lobo Antunes

Como já dissemos em outra ocasião, o termo Post-Modernismo encerra em si as potencialidades de um verdadeiro pužle hermenêutico (ARNAUT, 2002:13). Não cabendo embora no âmbito deste texto traçar o panorama histórico e conceptual da designação, não podemos, contudo, deixar de registar que a falta de consenso em torno do seu uso se situa, em primeiro lugar, no estabelecimento de fronteiras relativas às áreas a que se reporta. Daí a utilização quase sempre sinonímica dos termos Post-Modernismo e Post-Modernidade, independentemente da referência à Literatura (domínio para o qual preferimos o primeiro) ou a uma determinada época histórica e social. Em segundo lugar, a dificuldade reside na delimitação a quo de ambos os períodos. Em terceiro lugar, e intrinsecamente ligado ao ponto anterior, põe-se a questão das relações estabelecidas com o passado: continuidade? ruptura? continuidade e ruptura?

Finalmente, e sem pretendermos esgotar a lista de problemas levantados, encontra-se a indagação simultânea sobre a bondade e a validade da instauração do(s) novo(s) paradigma(s), cuja designação, para alguns, não é mais do que "um hífen cercado por uma contradição" (NEWMAN, 1985:17), ou uma espécie de unicórnio do século: uma criatura de que todos falam, mas "nunca chegou a ser muito vista pelos deleitosos bosques [literários] portugueses" (BARRENTO, 1990:31).

Seja como for, aceite por muitos, repudiado, talvez, por um número consideravelmente maior de escritores e ensaístas, o Post-Modernismo é, como afirma Fredric Jameson, um termo que não podemos deixar de usar (JAMESON, 1991:xxii). E no que respeita à Literatura Portuguesa, é hoje relativamente consensual que o seu início deve ter como ponto de referência a publicação de $O$ delfim, de José Cardoso Pires, em 1968. Com efeito, é nas páginas deste romance que confluem, ainda que por vezes em embrião, as principais marcas estéticas, e também ideológicas, do que, na esteira do movimento originário dos Estados Unidos, se consubstancia como uma diferente maneira de fazer e de entender a arte literária. 
Da nova literatura sobressaem os seguintes aspectos: a mistura de géneros e a decorrente fluidez genológica, num culto ostensivo e quase sempre subversivo; a insistente e crescente polifonia, em algumas situações a tocar as fronteiras do indecidível, da fragmentação e da (aparente) perda de narratividade; os exercícios metaficcionais, já presentes em romances cómicos e satíricos do século XVIII, mas agora renovados em grau e qualidade e alargados da escrita da história à re-escrita da História. Sublinhe-se, a propósito do modo como se processa a recuperação do passado, a imposição da paródia como elemento de fundamental importância para a deslegitimação das grandes narrativas que, num entendimento que nos parece pertinente, estendemos a códigos genológicos e periodológicos.

À semelhança do que sucedeu na constituição de períodos literários anteriores, também neste caso a implementação da novidade se traduz, de modo inevitável, em diferentes práticas de escrita, de acordo com o estilo e com as intenções de cada autor, tornando-se válido e aceitável pluralizar o termo e o conceito em apreço: Post-Modernismos e não somente Post-Modernismo. Mas, como acima indiciámos, a implementação do novo traduz-se, ainda, em relações simultâneas de oposição e de permanência de características já existentes em passados mais ou menos próximos ou mais ou menos remotos. Por isso, em estreita aliança com uma sempre subjectiva sensibilidade linguística, julgamos preferível recorrer ao prefixo 'post-', em detrimento do comum 'pós-'. Este parece apontar, de forma demasiado linear, para a ideia de 'algo que vem depois de', isto é, de alguma coisa que se institui com a marca de um corte absoluto, profundo e radical, em relação ao que o antecede. Por contraste, o prefixo latino sugere-nos uma amplitude relacional com vários passados que, de modo diverso, ecoarão no futuro que é, agora, o nosso presente.

A máxima non nova, sed nove (não coisa nova, mas de uma nova maneira), num efeito semelhante a uma manta de retalhos, parece ser, pois, a melhor forma de ilustrar a sensibilidade que se tem vindo a impor no panorama literário português. Esta imposição não implica, contudo, o desaparecimento de cultores de práticas romanescas afins de linhagens tradicionais, ou seja, de práticas romanescas (e também poéticas) tributárias tanto dos grandes clássicos do século XIX quanto dos mais recentes Teixeira de Pascoaes, Aquilino Ribeiro ou Raul Brandão, entre outros.

Relembre-se, a título exemplar da permanência do passado, O segredo de Leo- 
nardo Volpi, primeiro romance de Fernando Pinto do Amaral (2009), em cujas páginas se desenrola uma cativante e intensa história de amor, assumidamente construída de acordo com as (ainda) tradicionais expectativas de leitura, logo, conforme aos moldes mais antigos, pese embora a existência de alguns (sempre breves) desvios formais (relativos a inusitadas mudanças de linha, por vezes separadas por espaços em branco). Recorde-se também Agustina Bessa-Luís, em cuja escrita a herança de Camilo Castelo Branco ou de Raul Brandão pode aliar-se a eventuais tributos ao novo romance francês.

Refira-se, a propósito desta autora, ou melhor, ao que do seu estilo passa para a escrita de outros, um certo Mário Cláudio - de A quinta das virtudes (1990) ou de O pórtico da glória (1997) - em que os jogos conservadores se sobrepõem, apesar de tudo, ao paradigma post-modernista presente no efeito de montagem subversiva, descontínua, da narrativa. É o próprio autor, aliás, quem confessa o seguinte:

Noto muito ao longo de todo o meu trabalho de escrita que eu sou um nostálgico do romance tradicional e só não escrevo um porque não sei!... O que resulta de vanguarda, de modernidade, de uma nova proposta de escrita, é, no fundo, quanto a mim, um precipitado de várias coisas e o resultado da minha incapacidade de escrever um livro com princípio, meio e fim. Isso não quer dizer, por outro lado, que eu tenha em relação aos autores contemporâneos uma grande simpatia. Não tenho. Mas, cá está, há um problema edipiano que é difícil de resolver. Porque, se me faltar essa nostalgia, é certo que ficarei sem nada... (apud RODRIGUES, 1998:296)

Numa linha diametralmente oposta (ou quase) a esta confessada nostalgia encontramos, por conseguinte, livros como Um verão assim (1974), As batalhas do Caia (1995), ou qualquer um dos romances que compõem a Trilogia da mão (1993 / Amadeo, 1984, Guilhermina, 1986 e Rosa, 1988). Em Um verão assim, por exemplo, ensaiam-se os limites de uma exposição fragmentária, decorrente, na sua essência, e num primeiro nível, do jogo formal e semântico entre a poesia e a prosa, manipulações sintácticas e de pontuação incluídas. Não por acaso, Duarte Faria escreve que "Não se trata dum livro de contos nem dum romance de efabulação, mas, rigorosamente, dum poema de histórias onde, porém, "vêm decepadas as histórias"' (FARIA, 1975:72). Num segundo nível, 
a fragmentaridade é inevitável e irremediavelmente causada pelo carácter alucinatório que preside à construção das imagens e das figuras que povoam a globalidade do texto.

A subversão que assim se faz da arte de bem escrever tem evidentes efeitos nas capacidades hermenêuticas do leitor. Dele se exige, agora, um cuidado e uma paciência acrescidos, sob pena de não conseguir fazer sentido(s) de uma urdidura textual, de uma nova sensibilidade, que é, talvez, no conjunto dos títulos mencionados, a que se caracteriza por uma maior desordem semântico-estilística ou, por outras palavras, aquela em que de modo mais visível a narratividade parece e aparece perdida (ARNAUT, 2005:24).

A mesma apetência para aliar diferentes práticas de escrita é também passível de ser encontrada na produção ficcional de Lídia Jorge. Assim, se em romances como $O$ dia dos prodígios (1980) ou $A$ costa dos murmúrios (1988) ressaltam diversas ousadias semânticas e formais, diversos aspectos geradores da desagregação estrutural da narrativa ${ }^{1}$, em Notícia da cidade silvestre (1984) ou em A última dona (1992), a técnica utilizada dá origem, do ponto de vista do conceito de narratividade, a ficções estrutural e semanticamente mais coesas. Apesar disso, a verdade é que a capacidade transgressora de Lídia Jorge não desaparece, limitando-se, apenas, a assumir outras máscaras.

Mas a sensibilidade (nova) de que falamos não implica também, como já dissemos, a rígida obediência a um novo conceito de (uma nova) literatura, ou melhor, já que nos ocupamos da narrativa, a uma nova maneira de conceber o género romance. Por isso encontramos outros escritores tão semelhantes e ao mesmo tempo tão diversos, como Teolinda Gersão, Maria Isabel Barreno, Hélia Correia, Mário de Carvalho, Maria Gabriela Llansol, ou José Saramago e António Lobo Antunes, para lembrarmos apenas alguns dos autores que, tal como José Cardoso Pires, não resistiram à sedução pelo polémico ou, no mínimo, pelo estranho e pelo diferente.

O mesmo se pode dizer da escrita de Almeida Faria, em Cortes (1978), segundo volume de uma tetralogia começada em 1965, com A paixão, e completada com Lusitânia (1980) e Cavaleiro andante (1983). A não obediência à

1. Destacamos, entre outros, o peculiar uso da pontuação, a construção e a distribuição formal da narrativa por blocos de extensão variável, ou a tentativa de reprodução - pela apresentação em colunas paralelas - da simultaneidade de registos/diálogos. 
prática do modo tradicional de fazer ficção traduz-se, principalmente nos três últimos livros da tetralogia, num registo fragmentário já experimentado no polémico Rumor branco (1962). A desagregação da família, a diluição do que fora uma certa identidade nacional, também, e a necessidade de criar uma nova identidade, consubstanciam a ideia de cortes a vários níveis, mormente com o passado anterior a Abril de 1974. Estes cortes, que parecem encontrar correspondência na ideia de ruptura com uma certa tradição literária, prolongam-se, sem dúvida, em O conquistador (1990), romance onde a dessacralização da História e também do mito (de D. Sebastião), impõe a paródia tipicamente postmodernista, contrapondo o carácter intrépido do rei ao do seu homónimo, igualmente destemido, mas no que se refere à conquista de mulheres.

Refiram-se, ainda, Helder Macedo, em Pedro e Paula (1998), por exemplo, Fernanda Botelho, em As contadoras de histórias (1998), ou, entre outros, Nuno Júdice, em O enigma de Salomé (2007), e Manuel Alegre na "escrita em ziguezague” e fragmentária, "a única possível” (ALEGRE, 2010:71 e 101), de O miúdo que pregava pregos numa tábua. A leitura destas obras deixa também patente o afastamento em relação a algumas técnicas consolidadas no século XIX, nomeadamente, num eco de Jean-François Lyotard, a apresentação do que por convenção deveria permanecer impresentificável (LYOTARD, 1987:26), ou a falência tanto do conceito de narratividade quanto do modo objectivo de (re)construir personagens, tempos e espaços.

Se em O enigma de Salomé destacamos as considerações sobre o que é a escrita do romance, em Pedro e Paula salientamos o narrador que ostensivamente delimita a entrada num universo diegético onde os planos de contar são corrompidos. Para tanto, assume o poder sobre a escrita, hereticamente admitindo ter deturpado informações recebidas, recusando-se a facultar pormenores sobre a melancolia irónica do pai, por já o ter feito noutro livro (MACEDO, 1998:205, 105), ou propondo ao leitor duas versões relativas a um último encontro entre Pedro e Paula, acabando mesmo por escolher a "que conceptualmente [lhe] dá mais jeito" (MACEDO, 1998:84) (cf. ARNAUT, 1998:12).

Algumas das histórias de Fernanda Botelho (a segunda e a quarta), ensaiadas, escritas, corrigidas e comentadas pelas personagens-autoras-narradoras Ana, Eva e Isa, assumem a forma de pequenos contos perfeitamente autosuficientes e coerentes, tanto no que se refere à sua estrutura interna quanto no que respeita à densidade psicológica e à caracterização das personagens que 
nelas transitam. A irreverência e a perversão ensombram, porém, as narrativas em causa. Por um lado, porque se frustram as expectativas criadas pelo incipit de ambas, pois embora sugerindo vagamente um parentesco intertextual com conhecidos contos para crianças, a verdade é que a acção, conservando embora alguma coisa dessa semelhança de família, acaba por travestir-se de outras tonalidades, bifurcando-se em desenvolvimentos de onde se encontra ausente o tipicamente atemporal mundo de cores feéricas. Em lugar deste, surge uma história colorida por irónicos e jocosos enraizamentos num espaço-tempo prosaicamente humano e verosímil. Por outro lado, e num plano formalmente mais evidente, a ruptura é instaurada através de dois procedimentos peculiares e fundamentais: a inscrição de versões alternativas na segunda história (como acontece em Pedro e Paula de Helder Macedo) e a inclusão, em qualquer uma das histórias narradas, de comentários-debates finais entre as três narradoras, sempre de acordo com as possíveis variantes e alternância de sujeitos permitidas pela fórmula 'Assim falou $X, Y$ corrigiu, $Z$ gravou'.

No caso de José Saramago (cf. ARNAUT, 2008a), cuja produção romanesca podemos também inserir no âmbito de um impulso post-modernista de índole moderada (o que pressupõe, como veremos, um outro impulso, o celebratório), a diferença, o estranho, o novo, traduzem-se, desde o extraordinário romance Manual de pintura e caligrafia (1977), numa forte tendência para jogos metaficcionais. Referimo-nos à composição de obras que, através de diversas estratégias sempre passíveis de oscilação em grau e em número, revelam

uma hiperconsciência relativamente à linguagem, à forma do literário e ao acto mesmo de escrever ficções; uma constante insegurança no que se refere à relação entre ficção e realidade; um estilo paródico, meio a brincar, excessivo, ou ainda enganadoramente naif (WAUGH, 1988:2).

A autoconsciência sobre o carácter ficcional da obra de arte literária, os comentários da instância narrativa que desnudam os bastidores da ficção, ou, ainda, considerações sobre a literatura em geral, envolvem, necessariamente, a imposição (e a consequente aceitação por parte dos leitores) da inversão da fórmula de Coleridge sobre a regulação da crença na aceitação dos mundos do texto. Ao contrário da suspensão voluntária da descrença, pressuposta no pacto coleridgiano, o que a prática da metaficção implica é, agora, seguramen- 
te, o seu inverso: a suspensão voluntária da crença naquilo que se lê.

Cumpre sublinhar, porém, que se da técnica romanesca saramaguiana se destaca esta característica post-modernista, em alguns casos uma outra se sobrepõe: o aproveitamento paródico da História; o recurso a personagens e acontecimentos históricos, sim, mas numa linha de imitação/apropriação criticamente distanciada e com frequência usada como arma ideológica. A estreita aliança entre a vertente metaficcional, a paródica e a histórica introduz nuances no canónico subgénero do romance histórico, transformandoo, assim, no que Linda Hutcheon designa como metaficção historiográfica (HUTCHEON, 1991:21-22).

Refira-se, a título de exemplo, a História do cerco de Lisboa (1989), onde, à indagação e problematização metaficcional da (im)parcialidade da História se alia a apresentação de um outro possível lado do passado a que se reporta o romance - a conquista de Lisboa aos mouros, em 1147.

O primeiro aspecto é ilustrado quer por menções directas ao carácter viciado e selectivo do modo como se escreve a História (SARAMAGO, 1989:190-191, 124-125, 308, 347), quer pelos comentários que a instância narradora tece sobre o modo como o recognoscível Frei Rogeiro vai fazendo o relato dos acontecimentos, desvirtuando a verdade dos factos em favor do engrandecimento dos portugueses (SARAMAGO, 1989:200, 207). De igual modo, também os processos utilizados por Raimundo Silva para re-escrever a conquista da cidade são sujeitos a comentários que revelam a subjectividade, logo, a parcelaridade de quem re-escreve o legado histórico (SARAMAGO, 1989:232-233).

O segundo aspecto - a escrita do que poderia ter sido - decorre da manutenção das englobantes traves mestras da História, é verdade, mas "baixando de meio-tom todas as notas" (SARAMAGO, 1989:254). E se não é possível sustentar, de forma categórica, a versão em que os cruzados não auxiliaram D. Afonso Henriques na conquista da cidade de Lisboa (SARAMAGO, 1989:50, 109), é legítimo relativizar a sua participação na luta travada. A mudança de tom das notas históricas implica, por consequência, a concessão de maior importância ao papel desempenhado pelos soldados-guerreiros, isto é, a elementos do povo, o tal povo de que a História não reza. A atitude de rebeldia de Raimundo Silva permite, em última instância, numa espécie de mise en abyme intermundos (o real do autor e o ficcional da personagem), a ilustração da atitude post-modernista de José Saramago perante os inabaláveis factos da História. 
Ao mesmo tempo, com essa sua peculiar problematização dos factos históricos, no que respeita às dúvidas atinentes ao seu estatuto ontológico e epistemológico, corrobora-se a crise de legitimação das grandes narrativas de que fala Lyotard. Esta é ainda caucionada e exemplificada pela irónica e paródica utilização intertextual dessa outra grande narrativa que é o texto bíblico. Assim acontece, exemplarmente, em obras como $O$ evangelho segundo Jesus Cristo (1991) e Caim (2009), de José Saramago, ou A paixão do conde de Fróis (1986), de Mário de Carvalho. Neste romance, em que claramente se afirma a possibilidade de dispensar alguns elementos caracterizadores do passado (CARVALHO, 1993:173), a re-escrita do episódio do cerco a Almeida, pelos castelhanos, entre 7 e 25 de Agosto de 1762, dá azo a diversos momentos cómicos (tal como em Caim), de onde se não isentam interessantes ilações ideológicas (cf. ARNAUT, 2002:324-330).

Deste modo, e no que diz respeito à cena literária portuguesa, não julgamos ser conveniente aceitar as teorias relativas ao facto de, no (re)aproveitamento que fazem do passado histórico, os textos post-modernistas consubstanciarem uma redução apolítica da História à estética, com o consequente afastamento em relação a qualquer forma de ideologia (JAMESON, 1984:66; EAGLETON, 1985:61; NEWMAN, 1985:172).

É certo que não podemos negar a existência de obras em que o estético parece predominar. Sublinhamos, contudo, a forma verbal 'parece'. Se o leitor se predispuser a atentas e profundas leituras, transformando-se no 'legente' de que fala Maria Gabriela Llansol em vários livros², não é difícil descobrir que por detrás dos entrópicos jogos verbais e formais, constituintes do corpo vivo do texto, se escondem muitos dos múltiplos sentidos que, de um modo ou de outro, compõem vidas e espaços do Humano ou, em outros termos, de Portugal.

É assim que, em comentário denunciador do reconhecimento das dificuldades da leitura dos seus livros, Maria Gabriela Llansol não deixa de sublinhar a existência de sentidos profundos, sérios e pensados no seu "celebrante e jubiloso ofício da escrita" (SILVA, 2008:6):

2. Onde vais, drama-poesia? (2000), O começo de um livro é precioso (2003), O jogo da liberdade da alma (2003), Amigo e amiga - curso de silêncio de 2004 (2006), ou Os cantores de leitura (2007). 
Nunca me incomodou que me perguntassem o que ando a contar nos meus livros, apesar de ser daquelas perguntas que mais limitam o escritor — ter de dizer, em poucas palavras, o que só consegue dizer em tantas mais. Mas vou tentar dizer: eu ando a contar o mal-estar profundo dos seres humanos, dos animais e das plantas, ando à procura de um final feliz. Ando a ver se o fulgor que, por vezes, há nas coisas, é melhor guia do que as crenças que temos sobre elas, ou do que os pensamentos que, a propósito delas, nos ocorrem" (LLANSOL, 1994:5) (itálicos da autora).

É assim também que, em artigo escrito por ocasião da morte da escritora, Maria Fernanda Abreu não deixa de sublinhar a "sua empenhada e lúcida dimensão política, ou se se quiser, histórica” (ABREU, 2008:7).

De igual modo, a produção ficcional de António Lobo Antunes (cf. ARNAUT, 2009), que em entrevistas a Rodrigues da Silva e a Adelino Gomes confessou procurar um livro perfeito (ARNAUT, 2008b:215, 436), não deixa de conjugar um culto extremo de sistemáticos virtuosismos linguísticos e narrativos, com uma vertente de (não assumido) empenhamento ideológico.

Depois de ultrapassar as dificuldades criadas, por exemplo, pelo desmembramento de frases, pelas estranhas translineações, pelas suspensões semânticas inusitadas, pelas elipses lexicais e gráficas, pelo crescente labirinto de vozes $^{3}$, o 'legente' não deixará de verificar a sistemática ocorrência de temas que apontam para uma preocupação com problemas históricos, sociais e também humanos. A saber, o esmiuçar dos mais íntimos e esconsos recantos da alma, a denúncia das atrocidades cometidas pelo regime ditatorial ( $A$ ordem natural das coisas [1992], O manual dos inquisidores [1996], Ontem não te vi em Babilónia, [2006]); o questionamento da Guerra Colonial e do domínio português em África (igualmente patente em $A$ costa dos murmúrios [1988] de Lídia Jorge, Partes de África [1991] de Helder Macedo, A árvore das palavras [2000] de Teolinda Gersão, Vozes do vento [2009] de Maria Isabel Barreno); ou os efeitos de uma mal pensada descolonização (O esplendor de Portugal [1997], O meu nome é Legião [2007]).

3. Mencionem-se ainda os jogos entre a letra em tipo redondo e itálico, que nem sempre correspondem à mudança de voz, o sistemático uso de parêntesis ou a ousada inscrição de referências ao acto de escrever nas páginas que compõem o romance (do autor e das personagens a quem vai dando ou emprestando a capacidade para manipular o enunciado). 
Decorre do exposto, portanto, que admitimos na estética post-modernista a existência de um impulso de índole mais ousada - o celebratório -, no qual podemos incluir exemplarmente a ficção llansoliana e antuniana, a que brevemente fizemos referência. Largamente criativa, em todos os sentidos do termo, tal como já havia acontecido em Um verão assim, de Mário Cláudio, a escrita destes dois autores tenta avaliar o mundo sem, contudo, lhe impor uma ordem pré-estabelecida. A instituição de nexos temporais e espaciais, o deslindamento da rede de conexões que fazem o universo narrativo, em concomitância com a (re)composição das figuras-personagens que o povoam, ou a obtenção de sentido(s) a partir de longas e imbricadas frases, verbalizações delirantes, repetições, montagens e colagens é, seguramente, uma tarefa que agora se intensifica, quase até à exaustão da paciência e das competências do leitor (cf. FOKKEMA e BERTENS, 1986:39).

A nova prática ficcional não significa, nem implica, todavia, a morte do romance. O que sucede, sem dúvida, é o recurso a novas e diversas maneiras de (re)apresentar a realidade. E essas passam pela imposição de um compósito de (ainda) estranhas e emaranhadas lógicas discursivas, características do livro-rizoma e não do livro-raiz (DELEUZE e GUATTARI, 2006:56, 10, respectivamente), que podem levar ainda o seu tempo a ser reconhecidas de forma plena e desassombrada de preconceitos literários.

\section{Referências Bibliográficas}

ABREU, Maria Fernanda. "Uma cosmogonia narrativa". In Jornal de Letras, Artes e Ideias. 12 de Março, 2008:7-8.

ALEGRE, MANUEL, O miúdo que pregava pregos numa tábua. Lisboa: Dom Quixote, 2010.

ARNAUT, Ana Paula. António Lobo Antunes. Lisboa: Edições 70, 2009.

ARNAUT, Ana Paula. José Saramago. Lisboa: Edições 70, 2008 a.

ARNAUT, Ana Paula (ed.), Entrevistas com António Lobo Antunes. 1979-2007. Confissões do trapeiro. Coimbra: Almedina, 2008b.

ARNAUT, Ana Paula. "Mário Cláudio: aproximação a um retrato". In LEÃO, Delfim F.; FIALHO, Maria do Céu e SILVA Maria de Fátima (coords.), Mito clássico no imaginário ocidental. Coimbra: Ariadne, 2005:13-23. 
ARNAUT, Ana Paula. Post-Modernismo no romance português contemporâneo. Fios de Ariadnemáscaras de Proteu. Coimbra: Almedina, 2002.

ARNAUT, Ana Paula. "Helder Macedo, Pedro e Paula". In Artes \& Artes. Julho, 1998:16.

BARRENTO, João. "A razão transversal - requiem pelo pós-moderno”. In Vértice, Lisboa: (25): 31-36, Abr. 1990.

BOTELHO, Fernanda, As contadoras de histórias. Lisboa: Presença, 1998.

CARVALHO, Mário de. A paixão do conde de Fróis. 3ª ed. Lisboa: Caminho, 1993 [1986].

DELEUZE, Gilles e GUATTARI, Felix. Rizoma. Trad. Rafael Godinho. Lisboa: Assírio \& Alvim, 2006.

EAGLETON, Terry. "Capitalism, Modernism and Postmodernism”. In New Left Review, - (152): 60-72, Jul. - Aug. 1985.

FARIA, Duarte. "Um verão assim” (recensão). In Colóquio/Letras, Lisboa: (24): 72-73, Mar. 1975.

FOKKEMA, Douwe e BERTENS, Hans (eds.). Approaching Postmodernism. Amsterdam/Philadelphia: John Benjamins Publishing Company, 1986.

HUTCHEON, Linda. Poética do Pós-Modernismo. Trad. Ricardo Cruz. Rio de Janeiro: Imago, 1991.

JAMESON, Fredric. Postmodernism or The Cultural Logic of Late Capitalism. London, New York: Verso, 1991.

JAMESON, Fredric. "Postmodernism, or the Cultural Logic of Late Capitalism". In New Left Review, - (146): 53-92, Jul. -Aug. 1984.

LLANSOL, Maria Gabriela. Lisboaleipzig 2 - o ensaio de música. Lisboa: Rolim, 1994.

MACEDO, Helder. Pedro e Paula. Lisboa: Presença, 1998.

LYOTARD, Jean-François. O pós-moderno explicado às crianças. $2^{\mathrm{a}} \mathrm{ed}$. Trad. Tereza Coelho. Lisboa: D. Quixote, 1987.

NEWMAN, Charles. The Post-Modern Aura. The Act of Fiction in an Age of Inflation. Evanston: Northwestern University Press, 1985.

RODRIGUES, Ernesto. "Mário Cláudio: terceiro tríptico romanesco". In Colóquio/ Letras, Lisboa: (147-148): 293-298, Jan. 1998.

SARAMAGO, José. História do cerco de Lisboa. Lisboa: Caminho, 1989.

SILVA, Rodrigues da. "Maria Gabriela Llansol (1931-2008). A redescoberta começa agora". In Jornal de Letras, Artes e Ideias. 12 de Março, 2008:6.

WAUGH, Patricia. Metafiction. The Theory and Practice of Self-Conscious Fiction. London: Methuen, 1988.

Recebido em 23 de abril e aprovado em 26 de maio de 2010. 